\title{
Estrategias diagnósticas utilizadas para detectar deficiencias de hierro subclínicas y asociadas a enfermedades crónicas
}

\author{
Luz Stella Coy ${ }^{1}$ Msc, Martha Castillo' ${ }^{1}$ Msc, Ana Isabel Mora1 Msc, Ana Lucía Oliveros ${ }^{1}$ Msc, Zulay Vélez $^{2}$ \\ ${ }^{1}$ Docente- Investigador Universidad Colegio Mayor de Cundinamarca, ${ }^{2}$ Estudiante Universidad Colegio Mayor de Cundinamarca \\ Correspondencia: Icoyv27@unicolmayor.edu.co. \\ Recibido: 07-09-05 / Aceptado: 10-11-05
}

\begin{abstract}
Resumen
La homeostasis y las variaciones fisiológicas horarias en el metabolismo del hierro se constituyen en verdaderos desafíos para los expertos, quienes intentan diseñar pruebas altamente sensibles y específicas que cuantifiquen los niveles circulantes y de depósito de este elemento, su repercusión en la eritropoyesis, cuantificación de las proteínas, transportadores y receptores involucrados en el proceso, a fin de descartar la presencia de estados carenciales. Las deficiencias de hierro pasan por tres fases; las dos primeras son las más difíciles de identificar porque son subclínicas, más aún, cuando pueden cursar simultáneamente con enfermedades crónicas inflamatorias, infecciosas y neoplásicas que de por sí son anemizantes. En este trabajo se revisarán las principales pruebas de laboratorio utilizadas para la identificación de deficiencias de hierro, sensibilidad, especificidad, ventajas y limitaciones para su uso.

Palabras claves: anemia, enfermedades crónicas, deficiencia de hierro, diagnóstico, índice receptor transferrina-ferritina.
\end{abstract}

\begin{abstract}
Diagnostic strategies for detecting subclinical iron deficiencies and associated to chronic diseases: Due to the homeostasis and the hourly physiological variations in iron's metabolism, quantifying, both circulating and stored iron, has become a challenge for the experts that try to design highly sensitive and specific tests to quantify not only the levels of circulating and stored iron, but also its effects in erithropoiesis, and the proteins, transporters and receptors involved in the process in order to discard its deficiency. Iron deficiencies go through three stages; the first two are the most difficult to identify because they are sub-clinical and because they can appear simultaneously with chronic diseases inflammatory infectious, neoplacics which cause anemia. In this paper, the principal laboratory tests used to identify iron deficiencies will be reviewed, referring to their sensibility, specificity, advantages and their used limitations.
\end{abstract}

Key Words: anemia, chronic disease, diagnosis, iron deficiency, transferrin receptor-ferritin index.

\section{Introducción}

El hierro es uno de los nutrientes cuya deficiencia se considera un problema de salud pública. Se calcula que más de 3500 millones de seres humanos padecen de deficiencias de hierro (DH), tanto en forma subclínica como en forma de anemia ferropénica (AF). En países en vía de desarrollo el 56\% de las 
embarazadas, $53 \%$ de los escolares y $42 \%$ de los preescolares son anémicos. En Colombia, la prevalencia de AF es de $46 \%$ y $47 \%$ en embarazadas y escolares respectivamente (1). No tenemos registros de $\mathrm{DH}$ subclínicas en nuestro país salvo un estudio realizado en escolares y adolescentes en Medellín (2).

Considerando las etapas de crecimiento rápido, desarrollo psicomotor, embarazo y valoración integral del anciano es de gran importancia la detección temprana de las DH a fin de instaurar el tratamiento oportuno. Igualmente, es necesario identificar las DH que aún no se manifiestan clínicamente y que pueden padecer algunos adultos catalogados como sanos, de acuerdo a sus parámetros hematológicos primarios y secundarios, quienes pudieran ser erróneamente aceptados como donantes de sangre.

Este trabajo describe las pruebas de laboratorio más utilizadas para este fin, con sus ventajas y limitaciones. Además, intenta ilustrar otras técnicas relativamente novedosas en nuestro medio que se perfilan como herramientas útiles en la identificación de DH.

\section{Deficiencia de hierro}

La deficiencia de hierro es conocida como la carencia nutricional más común del mundo ya que es responsable del 50\% de las anemias (3). De esta problemática no escapan los países desarrollados pues a pesar de que en las últimas décadas han logrado disminuir la prevalencia de la anemia, la de $\mathrm{DH}$ subclínicas ha permanecido substancialmente (4).

Debe existir un balance entre la ingesta, absorción y las pérdidas de hierro, de lo contrario se puede generar DH. La absorción es regulada inversamente por el tamaño de los depósitos de hierro y directamente por la tasa de eritropoyesis. Estos depósitos corporales promedio en un adulto varían de 1 a 3 gramos. El balance, en cuanto a la absorción, se puede romper si no se suplen en forma adecuada las demandas de hierro. Éstas aumentan durante el embarazo, lactancia, niñez y adolescencia. La malnutrición y el parasitismo

www.unicolmayor.edu.co hematófago contribuyen igualmente a la ruptura de ese balance, generando $\mathrm{DH}$.

En cuanto a las pérdidas, no existe un mecanismo fisiológico que las regule. Se calcula que se elimina por recambio celular en piel, mucosas y tracto gastrointestinal principalmente, cerca de $1 \mathrm{mg} /$ día (5) y por menstruación $2 \mathrm{mg}$ /día (6). Estas pérdidas pueden aumentar en casos de hemorragias y anormalidades gastrointestinales como pólipos en colon, carcinoma de colon y cáncer gástrico. Esta última sigue siendo la primera causa de muerte por cáncer en Colombia.

El disbalance generado, bien sea por disminución en la ingesta, en la absorción o por aumento en la pérdida de este nutriente, genera paulatinamente estados carenciales de hierro los cuales cursan en tres etapas. La deficiencia de hierro fase I (DH I) está indicando depleción de los depósitos de hierro; en la fase II (DH II) la deficiencia ha afectado la eritropoyesis; y en la fase III o anemia ferropénica se ve comprometida la síntesis de hemoglobina.

\section{Anemia de enfermedades crónicas}

La anemia de enfermedades crónicas (AEC) es la segunda causa de anemia a nivel mundial. Las AEC comprenden un conjunto de patologías que activan el sistema inmune tales como las infecciones, inflamaciones, tumores y neoplasias. Tienen en común el hecho de generar citoquinas proinflamatorias y algunas antiinflamatorias (IL-10) que inducen disturbios en la homeostasis del hierro, dirigen a las células del sistema reticuloendotelial a tomar hierro de la circulación y almacenarlo limitando la disponibilidad de éste para ser utilizado en la eritropoyesis, alteran la vida media de los eritrocitos e inhiben la producción de eritropoyetina (7-9).

En condiciones inflamatorias algunas citoquinas liberadas como la Interleucina 6, Factor de Necrosis Tumoral alfa (TNF $\alpha)$, estimulan la síntesis de ferritina (10) y su consecuente depósito de hierro por parte de macrófagos y hepatocitos. Estas citoquinas y los lipopolisacáridos aumentan la expresión del 
transportador Divalente de Metal 1 (DTM1), a la vez que disminuyen la expresión de Ferroportin. DTM1 es un transportador transmembranal del hierro ferroso que estimula la captación de hierro libre y lo introduce a los macrófagos. El ferroportin es una proteína transmembrana que exporta hierro desde los enterocitos duodenales después de que el metal ha sido oxidado por la enzima ferroxidasa.

Por su parte, la IL-6 y los lipopolisacáridos inducen la producción de Hepcidin. Este hepcidin producido en los hepatocitos es un péptido antimicrobiano y antimicótico que incrementa su expresión como proteína reactante de fase aguda en respuesta a procesos inflamatorios e infecciosos (11). Inhibe la absorción de hierro en el intestino y no deja liberarlo por el sistema mononuclear fagocítico, disminuyendo la disponibilidad de hierro. Este efecto puede ser un mecanismo de defensa del huésped contra la invasión de microorganismos (12). En general, todas las citoquinas proinflamatorias ejercen un efecto negativo sobre la diferenciación de los precursores eritroides, sobre la producción de eritropoyetina y contribuyen al defecto de la utilización del hierro.

Por lo anterior, se entiende que las AEC son un grupo de desórdenes clínicos crónicos que se manifiestan con hipoferremia e hiperferritinemia (Figura1), complicando la identificación de pacientes con AEC que cursan simultáneamente con DH.

\section{Ferritina}

Los depósitos de hierro se almacenan intracelularmente como ferritina y hemosiderina, fundamentalmente en el sistema reticuloendotelial del bazo, hígado y médula ósea. Cada molécula de ferritina contiene alrededor de 2500 átomos de hierro aunque puede contener hasta 4500 átomos, en forma de cristales de hidróxido fosfato férrico. La hemosiderina está químicamente emparentada con la ferritina, de la que difiere únicamente por su insolubilidad en agua. Aunque ambas proteínas son inmunológicamente idénticas, la hemosiderina contiene un $30 \%$ más de hierro.

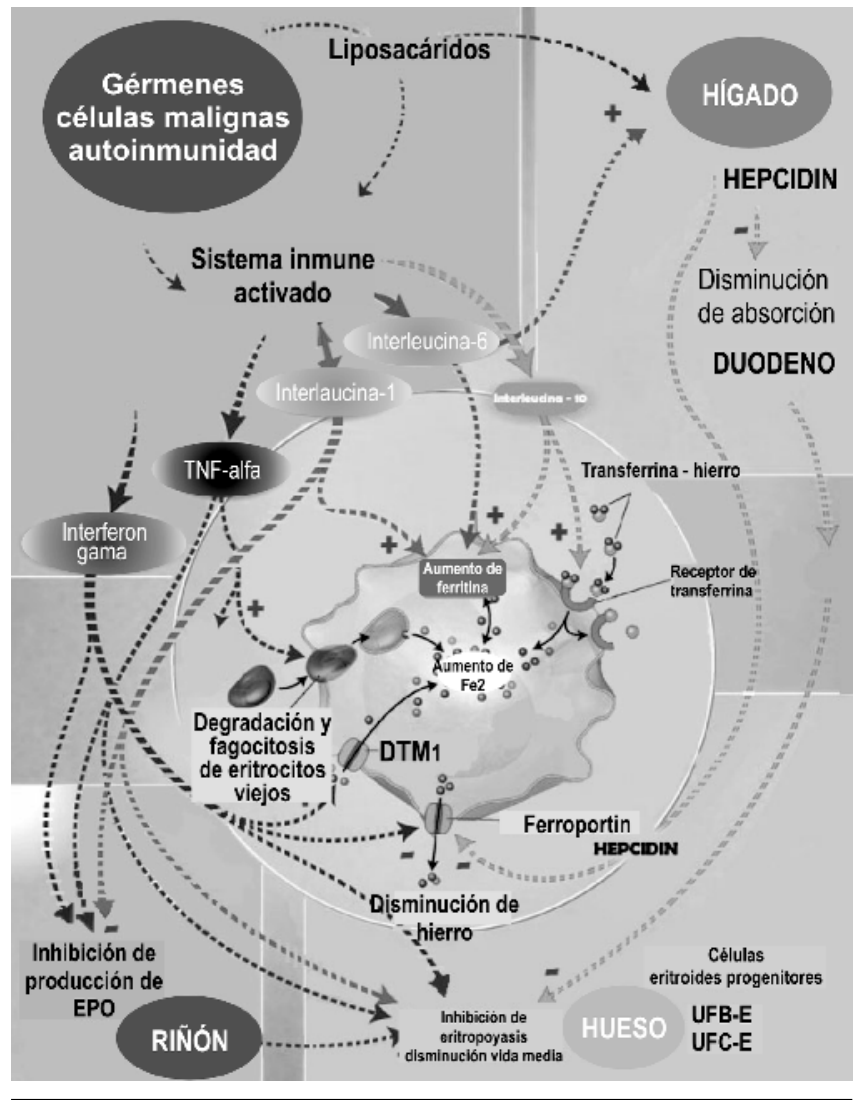

Figura 1. Mecanismos inmunológicos inductores de anemia durante las enfermedades crónicas. DTM1, Transportador divalente de metales 1; EPO, Eritropoyetina; TNFá, Factor de necrosis tumoral alfa; +, Estimulación; -, Inhibición.

La molécula de apoferritina es un heteropolímero de 24 subunidades de 2 tipos diferentes: $\mathrm{L}$ y H, con un peso molecular de $20 \mathrm{kDa}$ cada una, formadas por 4 cadenas helicoidales. Dependiendo del contenido de subunidades que conforman la molécula, se establece la existencia de gran variedad de isoferritinas, las que se dividen en 2 grandes grupos: isoferritinas ácidas (ricas en cadenas H) localizadas en el corazón, los glóbulos rojos, los linfocitos y los monocitos; y las isoferritinas básicas (ricas en cadenas L) predominantes en el hígado, el bazo, la placenta y los granulocitos. Conjuntamente las cadenas $\mathrm{H}$ y L cooperan en la captación del hierro, mientras las subunidades $\mathrm{H}$ poseen una mayor velocidad de captación y promueven la oxidación del hierro, las L promueven la formación de un núcleo de hierro dentro de la molécula.

La función primordial de la ferritina es asegurar el almacenamiento intracelular de hierro para su posterior 
utilización en la síntesis de las proteínas y enzimas. Sus niveles séricos han sido considerados como la mejor prueba para el diagnóstico de DH ya que su concentración es proporcional a los depósitos de hierro total (13). Sin embargo, diversas situaciones como la presencia de enfermedades crónicas, infecciosas, inflamatorias o neoplásicas alteran sus niveles por ser un reactante de fase aguda, como ya se mencionó anteriormente, complicando su utilización e interpretación en DH que cursen simultáneamente con esas patologías.

Por otra parte, el punto de corte de la Ferritina sérica como indicador de DH es muy controvertido. Dicho punto se estableció en $15 \mathrm{ng} / \mathrm{mL}$ (ELISA) sin distinción de géneros $(13,14)$ con el inconveniente de brindar una sensibilidad menor del $25 \%$ para identificar DH y $73 \%$ para identificar sujetos con $\mathrm{AF}(15)$, la especificidad es alta (98\%) utilizando el punto de corte convencional. Esta prueba ha sido utilizada simultáneamente con la concentración de $\mathrm{Hb}$, como tamizaje para identificar DH en poblaciones extensas (16). Sin embargo, la gran mayoría de estudios han encontrado puntos de corte muy superiores confirmados con tinción de médula ósea $(15,17,18)$. Si se aumenta el punto de corte a $30-35 \mathrm{ng} / \mathrm{mL}$, la sensibilidad puede aumentar a $92-94 \%$ con un valor predictivo positivo del 92\% (18,15). En ancianos, el nivel sérico de ferritina aumenta con la edad $(19,20)$ y el punto de corte óptimo sugerido es de 50-60 ng/mL (21-23). Igualmente, el punto de corte hallado para identificar estados que cursen simultáneamente con DH y AEC es de $153 \mathrm{ng} / \mathrm{mL}$ y para $\mathrm{DH}$ con malignidad no hematológica de $257 \mathrm{ng} / \mathrm{mL}$ (18).

Las pruebas para determinar los niveles de ferritina sérica incluyen radioinmunoensayos, ensayos inmunofluorométricos, imnumoenzimáticos y nefelométricos. Fue hasta 1991 que se estableció y estandarizó la calibración óptima de la prueba (24).

Ha sido un gran reto transportar y conservar las muestras tomadas de lugares rurales y apartados, sin que se alteren los niveles de ferritina sérica. Por eso, Flowers intentó determinarla en sangre total a partir de una gota de sangre capilar recolectada en papel de filtro. Comprobó la ineficacia del método al observar que es tres veces mayor la concentración de ferritina en sangre total que en suero por la contribución de le ferritina eritrocitaria (25). Sin embargo, el método para determinar la ferritina a partir de suero obtenido de sangre venosa y capilar recolectada en papel de filtro ya ha sido validado en ciudad de Guatemala (26) y Sri Lanka (27). Este método tiene la ventaja de obtener la muestra de una forma mínimamente invasiva, siendo ideal para niños. La forma de recolección permite almacenar las muestras a temperatura ambiente sin que se alteren durante cuatro semanas siempre y cuando sean guardadas en bolsas plásticas herméticas con desecante (28). Más aún, en las muestras que se conservan a $4^{\circ} \mathrm{C}$ durante un año, no se ha demostrado pérdida o deterioro de la actividad proteica (29). Por lo tanto, es un método confiable, económico, que se puede utilizar como tamizaje en aquellas regiones rurales con alta incidencia de DH.

\section{Receptor de transferrina}

El hierro juega un papel vital en la maduración, crecimiento y división celular. El transporte extracelular y el depósito dinámico de hierro en el cuerpo son logrados por su enlace a una proteína transportadora específica, la Transferrina. Virtualmente todas las células de mamíferos (30-36) excepto los eritrocitos maduros tienen un receptor que media en el flujo de hierrotransferrina desde el depósito extracelular hacia las células del cuerpo, el Receptor de Transferrina (TfR)). La cantidad de TfR refleja el potencial de proliferación celular (37). Pacientes con anemia aplástica o ablación de médula ósea tienen $40 \%$ de los niveles de TfR normal, por lo que se deduce que los precursores eritroides contribuyen con el $60 \%$ de TfR plasmático. Es así, como la principal fuente de TfR son las células eritropoyéticas de la médula ósea y los reticulocitos circulantes que pierden sus receptores al perder el núcleo durante su maduración. 
Existe otra forma de receptor, el TfR2, el cual es una proteína transmembrana que posee un $66 \%$ de homología con el TfR. Se encuentra casi exclusivamente en el hígado, es capaz de unir la transferrina y transportar hierro. Su función en el metabolismo férrico es poco conocida, aún cuando se ha postulado su importancia en la captación de hierro vía transferrina por el hepatocito, ya que es en este órgano donde su expresión es mucho mayor que la del TfR.

El genoma para TfR y transferrina (Tf) se localiza en el cromosoma 3. El TfR es una glicoproteína transmembranal, unida por enlaces disulfuro entre dos dímeros idénticos con peso molecular de $85 \mathrm{KDa}$ y 760 a.a. Cada cadena polipeptídica se encuentra glicosilada y rica en ácido palmítico al interior de la membrana y con un sitio fosforilado en su porción intracelular. Un enlace arginina-leucina, aminoácidos 100 y 101, en el extremo distal del segundo enlace disulfuro es susceptible a la proteolisis lo que produce una proteína transmembranal de sólo 11KDa más una proteína corta de 660 aminoácidos, el receptor soluble de transferrina (sTfR), circulante en el plasma (38). Existe conflicto acerca de la naturaleza de la proteasa encargada del proceso. Igualmente se desconoce la vida media en la circulación del sTfR. Una vez sTfR está en circulación se enlaza con Tf formando el complejo sTfR-Tf (38). La forma predominante de sTfR es la dimérica enlazada en su mayoría a la Tf diférrica y en menor proporción a la Tf monoférrica (39) siendo nula su afinidad de enlace a la apo-Tf. Los niveles de sTfR nos permiten conocer la cantidad de TfR total ya que sTfR es producto de la proteolisis del TfR celular y guardan una relación directa entre sí $(40,41)$.

El mecanismo de ingreso del hierro por medio del TfR involucra una alta afinidad del receptor por la transferrina diférrica. El complejo TfR-transferrina es internalizado e integrado a los endosomas y posteriormente el hierro es liberado por un cambio en el $\mathrm{pH}$ del endosoma al citosol con el complejo TfRapoferritina, el cual retorna a la superficie celular (Figura 2). En la superficie, la apotransferrina se di- socia para ser reemplazada por una transferrina diférrica, repitiéndose el ciclo.

El TfR controla la entrada de hierro a la célula (42). Los dos factores que modulan la cantidad de receptor celular y por consiguiente la cantidad de receptor circulante son: el estado del hierro tisular y la actividad eritropoyética. Puesto que, la concentración circulante de sTfR es proporcional a la concentración celular total de TfR, los niveles de sTfR se utilizan para monitorear la tasa de eritropoyesis proveyendo una medida cuantitativa del estado funcional del hierro. La elevación de sTfR en la deficiencia de hierro (DH) (43), es debido a que las células eritroides deben ser más competitivas para obtener los requerimientos mínimos de hierro.

El principal valor de TfR radica en la posibilidad de realizar un diagnóstico diferencial entre anemias microcíticas. Los valores de sTfR se encontrarán elevados en caso de ferropenia (44) reflejando el grado de deficiencia de hierro en los precursores eritroides de la médula. En un estudio realizado por Skikne y cols. en el que se sometió a flebotomía seriada a hombres sanos, se observó que la ferritina sérica decrece cuando los depósitos de hierro disminuyen (DH I) y los sTfR aumentan siempre y cuando la deficiencia sea suficiente para interferir con la eritropoyesis $(\mathrm{DH}$ II) sin que aún aumenten marcadores tisulares de hierro como saturación de transferrina, volumen corpuscular medio y protoporfirina eritrocitaria (45), lo que hace que sTfR se convierta en una prueba invaluable para distinguir entre deficiencias de hierro tipo I de las tipo II tal como ocurre en casos durante la niñez, adolescencia y embarazo donde los depósitos de hierro pueden estar disminuidos sin que la eritropoyesis esté aún comprometida.

Una de las principales dificultades en el laboratorio es la distinción entre anemias microcíticas por deficiencias de hierro de las anemias por enfermedades crónicas (AEC), especialmente cuando ambos desórdenes están presentes simultáneamente ya que por ser un reactante de fase aguda, la ferritina sérica 




Figura 2. Proceso de almacenamiento de hierro en forma de Ferritina. 1. Unión del hierro a la apotransferrina para formar transferrina diférrica. 2. Unión de la transferrina diférrica plasmática a los receptores de transferrina localizados en la superficie celular. 3. Invaginación de la membrana celular con los complejos receptor de transferrina- transferrina en su interior. 4. Fusión de la membrana celular formando una endovesícula ácida. 5. Fusión del endosoma con la vesícula ácida. 6. Liberación del hierro y aumento de la afinidad de la apotransferrina por su receptor. 7. Transporte del endosoma con los complejos receptor-apotransferrina a la superficie celular. 8. Liberación de la apotransferrina del receptor en un ambiente con pH neutro.

estará aumentada. A pesar de que estudios in vitro han sugerido que las citoquinas inflamatorias reducen la expresión celular del TfR, in vivo los sTfR tienen la ventaja de diferenciar entre una situación y la otra $(46,17)$ al no alterarse en situaciones de infección o inflamación aguda o crónica y de su escasa variabilidad biológica diaria, inferior a la ferritina, hierro sérico e índice de saturación de transferrina.

Los sTfR son útiles para predecir la respuesta que se obtendrá en pacientes con anemia por Insuficiencia renal crónica si se les administra eritropoyetina (EPO). Si los niveles de sTfR son bajos y la ferritina está en el límite superior normal o alta, estaría indicando baja actividad eritroide con adecuado almacenamiento de hierro, lo que sugiere que es ventajoso iniciar un tratamiento con EPO. En cambio si sTfR son bajos y la ferritina está en el límite inferior normal o baja, indicaría que hay de base una deficiencia en los depósitos de hierro por lo tanto el manejo de elección sería la administración de hierro más no la de EPO. Sin embargo, sTfR no es un buen indicador del éxito del tratamiento con EPO pues aumentaría tanto en la supresión de la eritropoyesis por deficiencia de hierro como en la eritropoyesis aumentada. Podría ser un buen predictor en estos casos si los niveles de sTfR aumentan más del $20 \%$ a las dos semanas del inicio del tratamiento 
con EPO, con relación a los niveles de sTfR antes de comenzar el mismo.

Aún cuando el foco de interés de sTfR radica en la detección de deficiencias de hierro, otras condiciones alteran sus niveles. En general, desórdenes con eritropoyesis reducida como la anemia aplástica o ablación de médula ósea disminuyen los niveles de sTfR $(44,47)$, al igual que los desórdenes que cursan con sobrecarga de hierro (48) como la hemocromatosis. Los desórdenes con eritropoyesis aumentada tales como las anemias hemolíticas $(44,47)$ y betatalasemia (49), aumentan los sTfR, al igual que las eritropoyesis inefectivas como el síndrome mielodisplásico y anemia megaloblástica (50).

Uno de los grandes problemas para detectar sTfR es la ausencia de estandarización internacional de los inmunoensayos utilizados para cuantificar los sTfR. Kohgo y cols. fueron los primeros en desarrollar la técnica por radioinmunoensayo para determinar los niveles séricos de sTfR (43). Sin embargo, algunas técnicas utilizan TfR purificados y aislados de suero como calibradores (48), otras utilizan complejos TfRTf aislados de TfR placentario (44) (47). Este último sistema de calibración simula de manera más cercana la forma en que in vivo circula TfR, el cual ordinariamente circula unido a la transferrina y en forma muy escasa en estado libre. La situación se complica al considerar que los depósitos de hierro alteran los resultados de estas pruebas (39). En general, la sensibilidad y especificidad de esta prueba para identificar DH II es del 97\% y 88\% respectivamente.

Se están haciendo esfuerzos para introducir una forma novedosa de cuantificar los niveles de STfR fuera del laboratorio a partir de una gota recolectada en papel filtro $(25,51)$. Aún cuando los costos disminuyen, la sensibilidad de esta técnica es discutible (52).

\section{Índice receptor soluble de transferrina-ferritina}

En vista de que las pruebas diagnósticas de rutina (Volumen Corpuscular Medio, Velocidad de Sedimentación Globular, Porcentaje de Reticulocitos circulan- tes, Hierro sérico, Transferrina sérica, Saturación de transferrina, Protoporfirina eritrocitaria), son poco sensibles para la identificación de DH subclínicas (45), DH que cursan con enfermedades crónicas o infecciosas, o DH en los ancianos (53), la Ferritina y los sTfR ocupan un lugar privilegiado.

Sin embargo, sTfR disminuye no solamente al suprimirse la eritropoyesis sino también en sobrecarga de hierro $(54,48)$ convirtiéndose en una variable de confusión. Igualmente ocurre con la ferritina, la cual disminuye en DH pero si un sujeto cursa con DH y enfermedad crónica, inflamación o disfunción hepatocelular, aumentará a pesar de la DH.

Estas variables de confusión limitan la sensibilidad y especificidad de estas pruebas. Por esto, Skikne intentó relacionar la potencialidad de la ferritina para reflejar el estado de depósito de hierro con la de sTfR el cual refleja la actividad eritropoyética por medio de la razón sTfR-Ferritina obtenida al dividir sTfR en la ferritina sérica (sTfR/Ferritina) (45). Con esta relación se aumentó de una forma poco significativa la sensibilidad y especificidad para el diagnóstico de DH.

Posteriormente, Punnonen introdujo el índice sTfRF como una combinación obtenida de la relación sTfR/ $\log$ Ferritina (17). Comprobó que este índice es altamente sensible y específico en la identificación de DH que cursan simultáneamente con anemias por enfermedades crónicas, infecciones y condiciones inflamatorias. Lo mismo se comprobó con ancianos (53) en quienes más del $50 \%$ de los que padecen $\mathrm{DH}$ presentan niveles de ferritina sérica aumentada o dentro de los límites normales. En estos sujetos, la ferritina sérica y las pruebas diagnósticas de rutina identifican DH con una sensibilidad del 16\% mientras que el índice sTfR-F lo hace con una sensibilidad del $88 \%$. Así mismo, Lee encontró que en adultos no ancianos, el índice sTfR-F identifica la DH de la anemia por enfermedades crónicas, inflamatorias e infecciosas, con una sensibilidad del $100 \%$ y especificidad del $98 \%$ frente al $97 \%$ y $88 \%$ respectivamente brindado por sTfR. Para que la 
ferritina logre una sensibilidad del $94 \%$, en estos casos, se debería aumentar en más de 12 veces el punto de corte sugerido por los correspondientes insertos, es decir, aumentarlo a $153 \mathrm{ng} / \mathrm{mL}$ (18).

En cuanto a la identificación de DH en malignidad no hematológica, el índice sTfR-F sigue siendo la prueba más sensible, obviando que la prueba "gold standard" es la biopsia de médula ósea. En estos casos, el índice tiene una sensibilidad y especificidad del $77 \%$, reflejando esto que la patogénesis de la anemia causada por cáncer no es clara. En esta patología, se puede disminuir la vida media de los eritrocitos y simultáneamente existir una falla compensatoria a nivel de la médula ósea causada por el aumento de citoquinas (48), disminuir la expresión celular de sTfR y suprimir la movilización del hierro.

Los primeros estudios realizados para establecer la utilidad del índice sTfR-F en el diagnóstico de DH subclínicas y establecer los rangos para dicho parámetro fue Suominen (56). Determinando sTfR por ELISA y la ferritina sérica por inmunofluorometría, encontró que un índice menor de 1.8 descarta la presencia de DH; entre 1.8 y 2.2 indica DH estado I (agotamiento de los depósitos de hierro); mayor de 2.2 es indicativo de DH estado II (eritropoyesis afectada por la $\mathrm{DH})$.

El índice sTfR-F es de gran utilidad para identificar DH en casos en que la ferritina sérica y sTfR estén dentro de valores limítrofes de normalidad, en enfermedades crónicas, infecciosas e inflamatorias y en ancianos. En general, este índice nace ante la evidente necesidad clínica de detectar DH por métodos altamente sensibles, que no sean invasivos, dolorosos y costosos como la biopsia de médula ósea con tinción de azul de Prusia, la cual es considerada el "gold standard" para la identificación de este tipo de alteraciones.

\section{Biopsia de médula ósea con tinción de Azul de Prusia}

En esta prueba, las muestras se extraen generalmente del esternón o la cresta iliaca. La tinción pone de manifiesto la presencia de hemosiderina en el citoplasma de cualquier tipo de célula, la cual aparece bajo la forma de gránulos de intenso color azul. La determinación del hierro medular tiene gran interés en el diagnóstico precoz de la ferropenia. Normalmente un 10 a $40 \%$ de eritroblastos son sideroblastos. Si se observa menos del $10 \%$ de eritroblastos teñidos, se considera suficiente evidencia de $\mathrm{DH}$; si se observa menos del $5 \%$ se confirma la presencia de AF (57).

Esta prueba es confirmatoria para identificar anemias por DH y por ende, para diferenciarlas de otras anemias. Su inconveniente radica en los altos costos, en el hecho de ser invasiva, dolorosa y de difícil ejecución.

\section{Conclusiones}

Se puede afirmar que el $92 \%$ de los sujetos aparentemente sanos con niveles de ferritina sérica $<30$ $\mathrm{ng} / \mathrm{mL}$ padecen de DH. En los sujetos que padecen anemia de enfermedades crónicas, inflamatorias e infecciosas, niveles de ferritina $<150 \mathrm{ng} / \mathrm{mL}$ están indicando presencia de $\mathrm{DH}$, con una sensibilidad del 92\%. E1 Indice sTfR-F aún cuando identifica las DH con una sensibilidad del 100\%, puede tener su máxima utilidad en casos en que los niveles de ferritina y sTfR sean limítrofes, en la discriminación entre DH I y DH II, y en la confirmación de casos de DH que cursen simultáneamente con AEC. En los ancianos que estén siendo estudiados por anemia, es necesario recordar que la sensibilidad del Indice sTfR-F es del $88 \%$ para identificar $\mathrm{DH}$, por lo que en estos pacientes se debe confirmar la carencia de hierro por aspirado se médula ósea con tinción de Azul de Prusia si el índice es $<1.8$ (Figura 3).

Se desconocen aún, todos los procesos implicados en la anemia por malignidad no hematológica, lo que explica que el Indice sTfR-F no tenga un beneficio adicional al que brindaría la ferritina para la identificación de DH. Si la ferritina es $<260 \mathrm{ng} / \mathrm{mL}$ está indicando, con una sensibilidad del $77 \%$, la presencia de DH.

www.unicolmayor.edu.co 


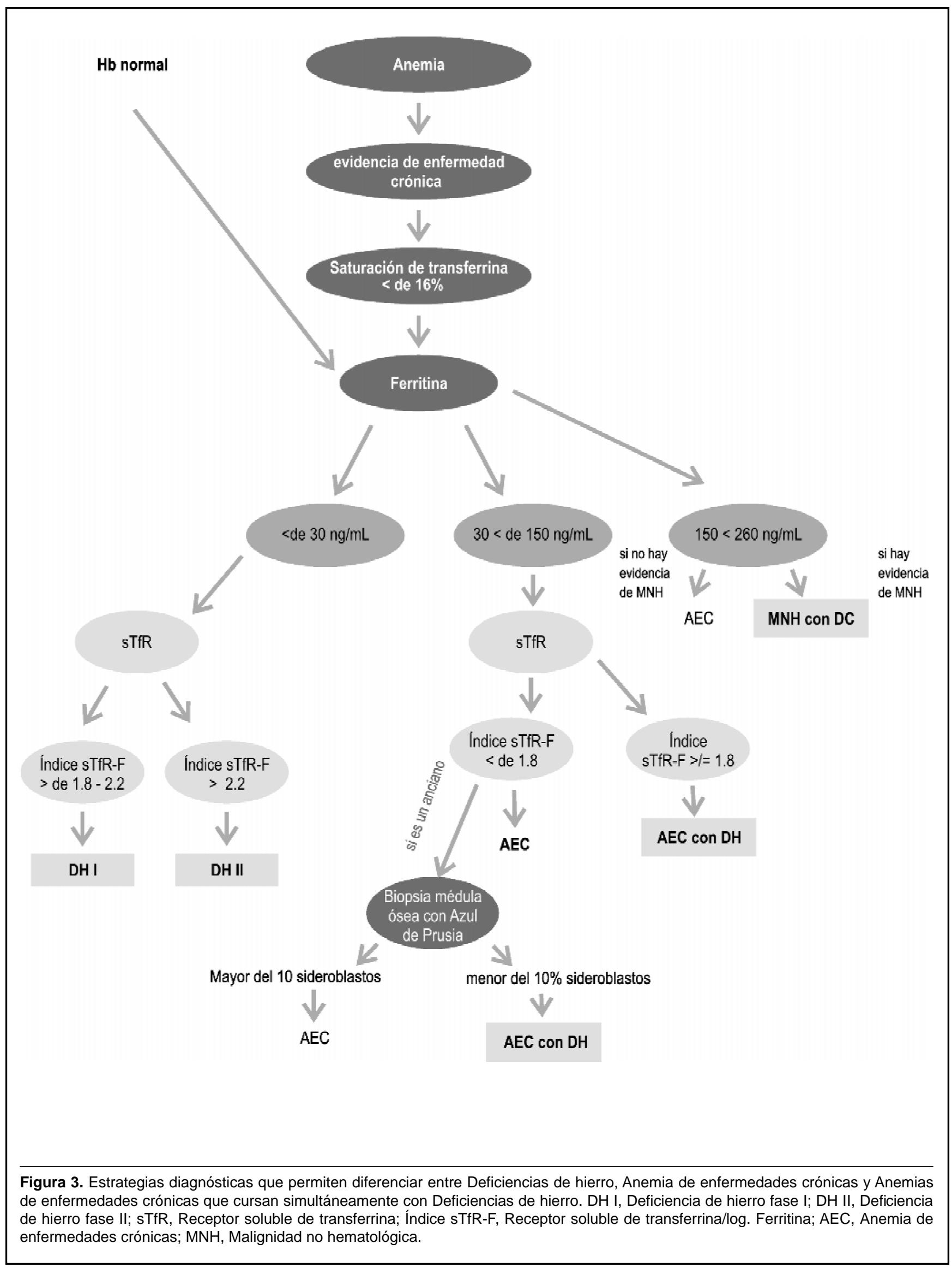




\section{Agradecimientos}

A la diseñadora industrial, María del Sol Poveda, por su ingenio para lograr que las ideas de las autoras quedarán fielmente plasmadas en las figuras de este manuscrito.

\section{Referencias}

1. Instituto Nacional de Salud de Colombia. Deficiencia de hierro, vitamina A y prevalencia de parasitismo intestinal en la población infantil y anemia nutricional en mujeres en edad fértil. Santa Fe de Bogotá, Ministerio Nacional de Salud; 1996.

2. Agudelo G, Cardona O, Posada M, Montoya M, Ocampo M, Marín C, et al. Prevalencia de anemia ferropénica en escolares y adolescentes, Medellín, Colombia, 1999. Pan Am J Public Health 2003; 13(6):376-86.

3. De Maeyer E, Adiels-Tegman M. The prevalence of anaemia in the world. World Health Stat Q 1985; 38:302-16.

4. Dallman PR, Yip R. Changing characteristics of childhood anemia (especial article). J Pediatr 1989; 114:161.

5. Cook JD, Skikne BS. Estimates of iron sufficiency in the US population. Blood 1986; 68:726-31.

6. Bothwell TH, Charlton RW. A general approach of the problems of iron deficiency and iron overload in the population at large. Seminars in Hematology 1982; 19:54.

7. Birgegard G, Hellgran R, Killander A, Stromberg A, Venge P, Wide L. Serum ferritin during infection. Scand J Haematol 1978; 21: 333-40.

8. Ferguson BJ, Skikne BS, Simpson KM, Baynes RD, Cook JD. Serum transferrin receptor distinguishes the anemia of chronic disease from iron deficiency anemia. J Lab Clin Med 1992; 119: 385-90.

9. Noe G, Augustin J, Hausdolf S, Rich IN, Kubaneck B. Serum erythropoietin and transferrin receptor levels in patients with rheumatoid arthritis. Clin Exp Rheumatoid1995; 13:445-51.

10. Ali M, Luxton AW, Walker W. Serum ferritin concentration and bone marrow iron stores: a prospective study. Scan Med Assoc J 1978; 118: 945-46.

11. Pigeon C. A new mouse liver specific gene, encoding a protein homologous to human antimicrobial peptide hepcidin, is overexpressed during iron overload. J Biol chem 2001; 276:7806-10.

12. Schaible U, Collins H, Priem F, Kaufman S. Correction of the iron overload defect in beta-2-microglobulin Knockout mice by lactoferrin abolishes their increased susceptibility to tuberculosis. J Exp Med 2002; 196:1507-13.

13. Lipschitz DA, Cook JD, Finch CA. A clinical evaluation of serum ferritin as an index of iron stores. N Engl J Med 1974; 290:1213-6.

14. Cook JD, Lipschitz DA, Miles LE, Finch CA. Serum ferritin as measure of iron stores in normal subjets. Am J Clin Nutr 1974; 27:681-7.

15. Mast A, Blinder M, Gronowsky A, Shumley C, Scott M. Clinical Utility of the Soluble transferrin receptor and comparison with serum ferritin in several populations. Clin Chem 1998; 44:45-51.

16. United Nations Children's Fund, United Nations University, World Health Organization. Iron deficiency anaemia assessment, prevention and control. A guide for programme managers. Geneva: WHO; 2001.

17. Punnonen K, Irjala K, Rajamäki A. Serum Transferrin Receptor and Its Ratio to Serum Ferritin in the Diagnosis of Iron Deficiency. Blood 1997; 89(3): 1052-7.

18. Lee E, Oh EJ, Park YJ, Lee H, Kim B. Soluble Transferrin Receptor (sTfR), Ferritin and sTfR/log Ferritin Index in Anemic Patients with Nonhematologic Malignancy and Chronic Inflammation. Clin Chem 2002; 48:1118-21.
19. Loria A, Hershko C, Konijin A. Serum ferritin in an elderly population. J Gerontol 1979; 34:521-4.

20. Casale G, Bonora C, Migliavacca A, Zurita I, de Nicola P. Serum ferritin and aging. Age Ageing 1981; 10:119-22.

21. Holyoake TL, Stott Dj, McKay PJ, Hendry A, McDonald JB, Lucie NP. Use of plasma ferritin concentration to diagnose iron deficiency in elderly patients. J Clin Pathol 1993; 46:857-60.

22. Joosten E, Ghesquiere B, Linthoudt H. Upper and lower gastrointestinal evaluation of elderly inpatients who are iron deficient. Am J Med 1999; 107:24-9.

23. Ruivard M, Boursiac M, Mareynat G. Diagnosis of iron deficiency: evaluation of the "soluble transferrin receptor/ transferrin" ratio. Rev Med Interne 2000; 21:837-43.

24. Worwood M, Thorpe SJ, Health A, Flowers C, Cook J. Stable lyophilized reagents for the serum ferritin assay. Clin Haematol 1991; 13:297-305.

25. Flowers $\mathrm{CH}$, Cook JD. Assessment of a Whole blood Spot method for the measurement of ferritin and transferrin receptor. FASEB J 1996; 10:A243.

26. Ahluwalia N, Bulux J, Solomons N, Romero-Abal ME, Hernández M, Boy E. Ferritin concentrations in dried serum spots prepared by Standard compared whith simplified approaches: a validation study in Guatemala City. Am J. Clin Nutr 2005; 81: 1366-71.

27. Ahluwalia N, Silva A, Atukorala S, Weaver V, Molls R. Ferritin concentrations in dried serum spots from capillary and venous blood in children in Sri Lanka: a validation study. Am J Clin Nutr 2002; 75: 289-94.

28. Ahluwalia N, Lönnerdal B, Lorenz S, Allen L. Spot ferritin assay for serum simples dried on filter paper. Am J Clin Nutr 1998; 67:88-92.

29. Flowers CH, Cook JD. Dried Plasma Spot Measurements of Ferritin and Transferrin Receptor for Assessing Iron Status. Clin Chem 1999; 45:1826-32.

30. Haddad E, Moura I C, Arcos-Fajardo M, Macher MA, Baudouin $\mathrm{V}$, Alberti O, et al. Enhanced expression of the CD71 mesangial Ig A1 receptor in Berger disease and HenochSchonlein nephritis: association between CD71 expression and Ig A deposits. J Am Soc Nephrol 2003; 14 (2): 327-37.

31. Brekelmans P, Van Soest P, Voerman J, Platenburg PP, Leenen PJ, Van Ewijk W. Transferrin receptor expression as a marker of immature cycling thymocytes in the mouse. Cell Inmunol 1994; 159 (2): 331-9.

32. Vannelli BG, Orlando C, Barni T, Natali A, Serio M, Balboni GC. Immunostaining of transferrin and transferrin receptor in human seminiferous tubules. Fertil Steril 1986; 45 (4): 536-41.

33. Zalata A, Hafez T, Schoonjans F, Comhaire F. The possible meanning of transferrin and its soluble receptors in seminal plasma as markers of the seminiferous epithelium. Hum Reprod 1996; 11 (4): 761-4.

34. Moos T. Brain iron homeostasis. Dan Med Bull 2002; 49 (4): 279-301.

35. Hayes GR, Williams A, Costello CE, Enris CA, Lucas JJ. The critical glycosylation site of human transferring receptor contains a high-mannose oligosaccharide. Glycobiology 1995; 5 (2): 227-32.

36. Gross S, Helm K, Gruntmeir JJ, Stillman WS, Pyatt DW, Irons RD. Characterizacion and phenotypic analysis of differenciacing CD34+ human bone marrow cells in liquid culture. Eur J Haematol 1997; 59 (5); 318-26.

37. Taylor A, Hogan BLM, Watt FM. Biosynthesis of EGF receptor, transferrin receptor and collagen by cultured human Keratinocytes and the effect of retinoid acid. Exp Cell Res 1985; 159: 47-54.

38. Shih YJ, Baynes RD, Hudson BG, Flowers CH, Skikne BS, Cook JD. Serum transferrin receptor is a truncated form of tissue receptor. J Biol Chem 1990; 265(31): 19077-81. 
39. Kato J, Kobune M, Kohgo Y, Fujikawa R, Takimoto R, Torimoto Y. Ratio of Transferrin (Tf) to Tf-Receptor Complex in Circulation Differs Depending on Tf Iron Saturation. Clin Chem 2002; 48:181-3.

40. Ahn J, Johnstone RM. Origin of a soluble truncated transferrin receptor. Blood 1993; 81: 2442-5.

41. Baynes RD, Skikne BS, Cook JD. Circulating transferring receptors and assessment of iron status. J Nutr Biochem 1994; 5:322.

42. Hoffbrand V, Lewis MS, Tuddenham E. Postgraduate Haematology. $4^{\text {th }}$ en. London: Butterworth Heinemann International Editions, 1999, p 23-46.

43. Kohgo Y, Niitsu Y, Kondo H. Serum transferrin receptor as a new index of erithropoiesis. Blood 1987; 70: 1955-8.

44. Flowers CH, Skikne BS, Covell AM, Cook JD. The clinical measurement of serum transferrin receptor. J Lab Clin Med $1989 ; 114: 368-77$.

45. Skikne B, Flowers C, Cook J. Serum transferrin receptor: A quantitative measure of tissue iron deficiency. Blood 1990; 75:1870-6.

46. Ferguson BJ, Skikne BS, Simpson KM, Baynes RD, Cook JD. Serum transferrin receptor distinguishes the anemia of chronic disease from iron deficiency anemia. J Lab Clin Med 1992; 19: 385-90.

47. Huebers HA, Beguin Y, Pootrakul P, Einspahr D, Finch CA. Intact transferrin receptors in human plasma and their relation to erythropoiesis. Blood 1990; 75: 102-7.

48. Khumalo H, Gomo Z, Moyo V., Gordeuk V, Saungweme T, Rouault $\mathrm{T}$, et al. Serum transferrin receptors are decreased in the presence of iron overload. Clin Chem 1998; 44:40-4.

49. Beguin Y, Clemens GK, Pootrakul P, Fillet G. Quantitative assessment of erythropoiesis and fuctional classification of anemia based on measurement of serum transferrin receptor and erythropoietin. Blood 1993; 81:1067-76.
50. Carmel R, Skikne BS. Serum transferrin receptor in the megaloblastic anemia of cobalamin deficiency. Eur J Haematol 1992; 49:246-50.

51. Vikstedt R, Lode P, Takala T, Irjala K, Peltola O, Pettersson $\mathrm{K}$, et al. Rapid One-Step Immunofluorometric Assay for Measuring Soluble Transferrin Receptor in Whole Blood. Clin Chem 2004; 50(10): 1831-3.

52. Zeng L, Sharieff W. Comments on Use of Combined Measures from Capillary Blood to Assess Iron Deficiency in Rural Kenyan Children. J Nutr 2004; 134:1844-5.

53. Rimon E, Levy S, Sapir A, Gelzer G, Peled R, Ergas D, et al. Diagnosis of iron deficiency anemia in the elderly by transferrin receptor - ferritin index. Arch Intern Med 2002; 162: 445-9.

54. Looker AC, Loyevsky M, Gordeuk VR. Increased Serum Transferrin Saturation Is Associated with Lower Serum Transferrin Receptor Concentration. Clin Chem 1999; 45: 2191-9.

55. Dowlati A, R'Zik S, Fillet G, Beguin Y. Anaemia of Lung cancer is due to impaired erythroid marrow response to erythropoietin stimulation as well as relative inadequacy of erythropoietin production. Br J Haematol 1997; 97:297-9.

56. Suominen P, Punnonoen K, Rajamäki A. Serum transferrin receptor and transferrin receptor-ferritin. Index Identify Healthy Subjects with subclinical iron deficits. Blood 1998; 92 (8): 2934-39.

57. Fairbanks VF, Beutler E. Iron deficiency. In: Beutler E, Lichtman MA, Coller BS, et al, edts. Williams Hematology. $6^{\text {th }}$ ed. New York, NY: Mc Graw Hill Medical Publishing Division; 2001:447-70. 